spent in obtaining their degree. Indeed, all too often, guidance means nothing more than sporadic contact with the supervisor. As one respondent stated: 'You depend $100 \%$ on your supervisor. If you are lucky, everything goes fine, but if not, you are lost.' In contrast, respondents who were effectively guided said that this created a collaborative and motivating atmosphere. They also noted that it saves a lot of time, as regular discussions are useful for planning future experiments, avoiding mistakes and staying focussed.

Publication requirements, unfair prolongation of thesis work and ineffective guidance can all cause a substantial delay in obtaining a PhD. Accordingly, the age at which candidates receive their title varies significantly in Europe. This causes problems for those who spend many years, and consequently graduate at a time when they consider starting a family and are in need of financial safety. Moreover, some 'older' respondents complained that age can be a negative factor when applying for a postdoctoral position or fellowship. In addition to alleviating such personal disadvantages, similar criteria are likely to promote the mobility of young scientists within Europe. By harmonising standards, universities and institutes would be more willing to accept each other's PhD programmes as equal. Thereby, individual PhD students could travel around more freely and gain valuable international experience at an early stage of their scientific careers.

The best institution to introduce such harmonisation would certainly be the European Union. The European Commission has a strong interest in promoting the movement of young sicnetists in order to create the 'European Research Area' that Philippe Busquin, the Commissioner for Research, described. Therefore, the Com-

mission has appointed a group of experts to identify obstacles hindering mobility within Europe. Currently, the group is investigating the acceptance of degrees throughout the EU. However, removing obstacles is not so easy. 'Individual member states consider that requirements they impose on their students are their own concern,' said Dr Georges Bingen, the

based on the quality of the work done, when graduation is justified. The European Commission could help to stimulate European synchronisation and assist thesis committees with their task, for example by promoting exchange programmes as mentioned above, or by drafting EU-wide valid guidelines for PhD requirements. A situation in which graduate students, regard-

Whereas the value of a PhD degree in the life sciences is considered equal, the time and difficulties involved in obtaining it vary excessively throughout Europe

European Commission's official responsible for the work of this group of experts, 'they are reluctant to accept centrally imposed rules.' A better way to create harmonisation, he said, would be to promote greater interaction between European research institutions.

To stimulate the exchange of students, the European Commission has recently launched a new scheme within the system of Marie Curie fellowships that supports PhD students wishing to perform part of their graduate studies abroad. The programme has started this year and will ultimately finance 5000 fellowships for PhD students. 'By stimulating such programmes,' Bingen said, 'an increasing number of students get a chance to interact with scientists from different member states. And, increased interaction will eventually lead to increased harmonisation.'

Whereas the value of a $\mathrm{PhD}$ degree in the life sciences is considered equal, the time and difficulties involved in obtaining it vary excessively throughout Europe. Harmonisation would be best promoted by the general implementation of thesis committees to provide guidance and to decide, less of the country they come from, walk similarly challenging paths will contribute to a more collaborative scientific atmosphere in Europe and thereby increase the international exposure young scientists receive. Such early international experience and exposure to different cultures and perspectives will produce better trained and experienced graduates, who are more able to meet the demands of the international scientific community.

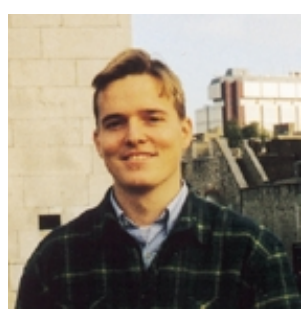

\section{Joep Muijrers}

The author is a $\mathrm{PhD}$ student at the European Molecular Biology Laboratory in Heidelberg, Germany, and a co-founder of Gene Bridges $\mathrm{GmbH}$.

E-mail: JoepMuijrers@Genebridges.com

DOI: 10.1093/embo-reports/kvd119

\title{
Trust, sensitivities and science
}

\section{Scientists, policy makers and representatives of interest groups met in Brussels to discuss the future of genetic research in Europe}

Biotechnology, driven by genome sequence analysis, is making ever greater strides in medical research. At the same time, however, many people feel threat- ened by these rapid developments and have raised objections against the further 
use of this technology. The public, particularly the consumer, feels excluded from the debate on how to apply the increasing store of knowledge in biology. Society wishes its views and opinions to nately, there is no rule that governs the 'acceptability' of such an action. It would seem that politics or society-if it so wishes-can do no more than introduce a law forbidding it.

\section{Interest groups welcomed scientific progress as a means to ease suffering, but remained surprisingly indifferent towards the needs of the poor}

be taken into account. To address this problem, the European Commission held a conference in Brussels from 6-7 November entitled 'Genetics and the Future of Europe'. For the first time under the auspices of the $\mathrm{EC}$, the stakeholders in the debate convened to do battle.

It was clear that the sectors of society which are likely to benefit most from advances in genetics embrace the new technologies as a glimmer of hope. Indeed, despite lingering ethical considerations particularly about prenatal diagnosis, embryo selection or gene therapy, genetics-derived technologies are largely viewed positively. However, not without reservations. Representatives of interest groups welcomed scientific progress as a means to ease the suffering of those they represent, but they remained surprisingly indifferent towards the needs of the poor in the third world.

The debate on the use of human genetic information is largely about ethical arguments, and it is emotionally driven by a deep belief in the sanctity of human life. It is easy to make a case for the medical use of genetic information when it saves lives. A frequently used example is Adam Nash who was conceived, after prenatal selection, to have the same immunological make-up as his elder sister Molly. Immediately after birth, cells were taken from his umbilical cord to treat Molly who suffers from a rare form of anaemia. Alastair Kent viewed the case as the parents' 'rational decision to have a normal child and give the first child a chance for a normal life.' Hence it is an example of a 'win:win' scenario and the 'humane use of technology' as Kent put it. Had the parents taken the opposite decision, they might have been accused of ignoring an existing technology that could have saved the life of their daughter. On the other hand, Adam Nash might grow up with the notion that he had simply been conceived as a 'spare part' for his less fortunate sister. Unfortufrom the Genetics Interest Group, UK,
The only way forward is to engage different sectors of society in a dialogue. Frank Mulcany of the European Disability Forum vigorously asserted that in the whirlwind of scientific developments, the individual, and the rights and sensitivities of the individual had been neglected. It would appear that interest groups are very

Trying to find a minimal consensus is a gruelling process but it is reassuring to witness a genuine debate among stakeholders

keen to be involved in debating the ethical problems of applications that might ultimately affect them. However, while playing their hand, they too often pursue their own interest at the expense of the needs of others. Indeed, while the benefits of biomedicine are not questioned, the further introduction of GM plants has been vehemently fought against-although the potential benefits to the third world are immense. 'The fastest growing population now is in Africa,' said Alex Kahn from the Institut Cochin de Génétique Moleculaire in Paris, 'and it has seen absolutely no benefits from advances in genetics.'

A dispute about a particular line of genetic research can no longer be solved in purely logical scientific or medical terms unless the technology is widely accepted as benefiting society. As John Martin from University College London noted, there is no framework to consider ground-breaking experiments. There is nobody to answer the question 'can I put a mouse gene into a human?' he said, referring to experiments done at his laboratory. Surely the only one way to answer this is to invoke a principle. And there are two possibilities: a human being has a soul or an essence and thus may not be so violated or a human being is simply a bag of genes and biochemical processes that can be treated like a machine. The right approach is neither of these, but rather something more intellectually taxing: a principle that embodies the sensitivity of the affected individuals, while recognising the enormous potential that medical genetics has to cure and prevent disease. Ultimately, it is only in dialogue with the public that such a principle can be formulated. It should not be forgotten that the desire to have the choice, and the desire to use that choice are different. In the case of Huntington's Chorea for instance, learning one's fate is of doubtful benefit. As Bernadette Moran, Development Officer of the Huntington's Disease Association of Ireland commented, before the test for Huntington's was developed, more than $60 \%$ of those at risk said they would take the test; after the test was made available the figure was $13 \%$.

Huntington's Chorea is also the subject of recent moves to make genetic test data

\section{The Ten Commandments for molecular biology}

This world is meant to be a place where people can live in peace and prosperity. Therefore:

1. Thou shalt not take science and technology as the highest value, but as instruments towards a goal.

2. Thou shalt not ignore public opinion.

3. Thou shalt not reduce society to a mere market place, but respect individuality.

4. Thou shalt not reduce public concern to a mere lack of information.

5. Thou shalt avoid industrial imperialism.

6. Thou shalt avoid scientific pluralism.

7. Thou shalt be transparent and trustworthy.

8. Thou shalt introduce ethics from the beginning of the introduction of a new product.

9. Thou shalt not boast or make unwarranted claims.

10. Thou shalt observe the precautionary principle, reduce risk to a minimum, and not play God. 
available to insurance companies in the UK and Ireland. As if it were not enough to be disadvantaged by carrying a predisposing allele, predisposed individuals might become discriminated against on purely economic grounds. But as the dis-

In the whirlwind of scientific developments, the individual, and the rights and sensitivies of the individual may have been neglected

cussion about the protection of genetic privacy in the USA and the UK demonstrates, science and medicine may be the first victims. People increasingly decide not to take necessary and beneficial tests because they fear being discriminated against on the basis of the result. 'Human rights should not be replaced by genetic rights,' Alex Kahn commented. On that, at least, all agreed.

The conference was not designed to produce any conclusions or policies. But at least it demonstrated democracy in action. Trying to find a minimal consensus is of course a gruelling process, but it is at least reassuring to witness a genuine debate among stakeholders. And what became clear in this debate was that the public lacks trust in their government and scientific research. Although there is no logical reason for this, the BSE scandal has shown that health and environmental scandals can easily backlash on the scientists involved. Thus, it must be made clear that scientists are not the cause of the evil. 'We did not create BSE, we explained it,' said David McConnell from the Trinity College in Dublin and an ardent proponent of genetics. Though this is true, one could not help but feel that at the end of the most eloquent defence of science given over the two days, the converted were still converted, whereas the unconverted were starting to leave early.

Research on GM plants has also become tarred with the BSE brush, and given that this technology has not yet provided tangible benefit to consumers in the West-pest or drought resistant crops, for example-it is not surprising that it is viewed with a scepticism that verges on paranoia. 'Man is what he eats; food is a societal and cultural thing that has much

\section{At the end, the converted were still converted, whereas the unconverted were starting to leave early}

to do with an individual's way of life,' said Egbert Schroten, from the University of Utrecht, 'If you systematically take out these emotional aspects from the debate, you will run into problems.' This naturally holds true for all new technologies. And with the authority of an ethicist and theologian, Schroten closed with his Ten Commandments for proper conduct of science with society. Scientists ignore them at their peril.

\section{Andrew Moore and Holger Breithaupt}

DOI: 10.1093/embo-reports/kvd130 